\title{
The Existence of Forests in Japanese Belief (Sociology Literature Study of Anime Miyori no Mori)
}

\author{
Rahmah Yuliani ${ }^{1 *}$, Mulyadi Budi ${ }^{2}$, and Fajria Noviana ${ }^{1}$ \\ ${ }^{1}$ Japanese Program, Linguistics Department, Faculty of Humanities, Diponegoro University \\ ${ }^{2}$ Japanese Program, Linguistics Department, Faculty of Humanities, Diponegoro University
}

\begin{abstract}
This research discusses the environmental issues and their relationship with the Japanese beliefs described in Japanese visual literature: anime Miyori no Mori. This animation story is full of messages about environmental preservation and environmental issues. The story Miyori no Mori teaches the audiences (especially children) the importance of protecting the forest and the impacts that will arise when the forest is destroyed and clearly illustrates how the forest is related to god's spirits in Japanese belief. This research aims to reveal the elements of that belief through the existence of the forest depicted in the anime Miyori no Mori. Qualitative approaches and sociology literature study as research methods analyses forests' critical role in Japanese people's beliefs. The research examined includes the elements of faith depicted in the anime Miyori no Mori, such as the role of gods, the existence of ancestral spirits, and even monsters in that forest. As a result, it will be known how important the role of forests is as part of the Japanese people's belief. It can be a solid reason for upholding environmental preservation, mainly to prevent their environment from covid-19 effects.
\end{abstract}

\section{Introduction}

Japan is known as a modern country with high technology and modern industrialization, but it is also known as a country concerned about nature and the environment. It proved to other countries that the industrialization that made modern life and high technology caused damage to the environment and can grow side by side if we have a concern for our environment. Japan's awareness of the environment can be seen from the Japanese people's behaviour, famous for their neat and clean, well-preserved natural environment, and from their involvement in international activities related to preserving nature and the environment.

Since 1990, Japan has played a role in overcoming global environmental problems, and their concern can be seen from Japan's active role in various world environmental agendas. Japan has actively hosted several international environmental conferences, such as the Third Session of the Conference of Parties (COP-3) of the United Nations Framework Convention on Climate Change (UNFCCC) in December 1997. This Conference's result of the Kyoto

* Corresponding author: yuliani.rahmah@live.undip.ac.id 
Protocol [1] and activities in the forestry sector, such as the International Expert Meeting on "Monitoring, Assessment and Reporting on the Progress towards Sustainable Forest Management," confirmed Japan as one of the leaders to conserve global forests.

\subsection{Forests in Japan}

Japan is the world's third-largest forest country. Japan has about 25.05 million hectares of forest. About 13.48 million hectares (about 50 per cent) are natural forests, 10.2 million hectares (about 40 per cent) are artificial forests, and the rest are plain wood and bamboo forests. With a forest area of about $66 \%$ (forest rate of about $70 \%$ ) as a national land area, it is one of the leading forest powers in the developed world [2]. Same with the islands in Japan, the largest forest area is on Hokkaido, while the smallest forest area is on. Okinawa. Apart from Hokkaido, there are other areas with extensive forests in Iwate and Nagano prefectures.

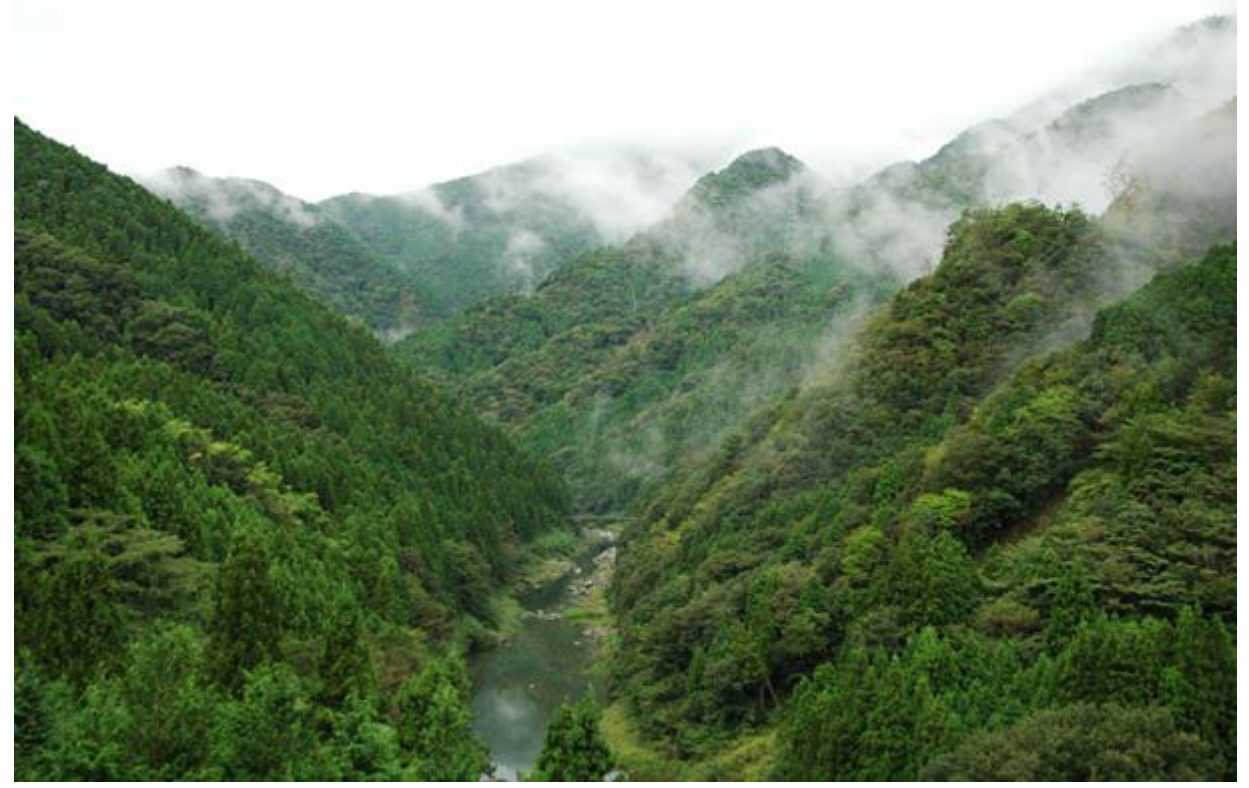

Fig. 1. Upper Yoshino River, (C), Tokushima Prefecture 2010 My forest.jp Photo Department.

Rots (2013) stated that Japan's forests are predominantly located in the mountain: $73 \%$ of the total land area is mountainous, most of which is covered by forest. The remaining $27 \%$ is used for living, industry and agriculture; these areas are very densely populated, and there is hardly any piece of non-mountainous land that is neither cultivated nor inhabited [3]. The existence of tropical forests and their ecological diversity cannot be separated from the Japanese community and the government's role to continuously protect and maintain these tropical forests. One example is described in the following article: "The diverse ecosystem surrounding the traditional Japanese rural community is called Satoyama. Although rich in flora and fauna, the woodland around villages is not a virgin forest but the product of many years of careful tending and stewardship by the resident. The Japanese people have been planting and maintaining forestland since the Jomon period" [4]. From that information, it can be seen that the Japanese people have carried out efforts to maintain the existence of forests for a long time. It is not only efforts made in the modern era when the issues such as global warming, illegal logging, or even the covid 19 disease problems have become global 
problems. The Japanese concern and commitment that has been carried out before the modern era cannot be separated from their belief in the teachings of their ancestors, which later became their identity.

The effort to protect the forest and the surrounding environment has also been taught to Japanese children from an early age when they start school. Japanese people believed that love for nature would be easier to cultivate when they were children. When they grow, love for nature will bring a desire to protect nature from damage permanently. The teacher instils a firm understanding that trees are essential elements that cannot be separated from human life, so humans must maintain and preserve them. To establish a harmonious relationship with the surrounding nature, since the first grade of elementary school, Japanese children learned subjects called seikatsu, namely the study of life sciences. This lesson aims to train children to be independent and skilled in living their lives. One of the targets of this subject is that children can recognize their relationship with nature [5]. It shows that the importance of forest existence for Japanese people is even rooted in all aspects of their community life.

Rots (2013) stated that Abe Auestad demonstrates that'forest' constitutes a powerful trope in Japanese literature, religion, and popular culture. Intimately connected with notions of Japanese history, culture and national identity, they carry profound ideological significance. That statement is in line with what we can find in modern Japanese life. Forests and their existence can be found in the themes of literary works and popular culture loved by Japanese youth, and one of them is animation. Greenberg stated that animation could be defined as a text bearing distinctive representational traits vis a vis cinema. Furthermore, he also said that the basic meaning of animation is its ability to convey concepts rather than objects. Thus, products such as anime, films, novels and other literary works can represent the culture of a nation [6]. In Japan, there is much anime with environmental themes, and one of them is an anime entitled Miyori no Mori, which will be the object in this study.

Miyori no Mori, which means "Miyori's Forest," is an animated film director by Nozo Yamamoto. This animation was adapted from the manga with the same title by Hideji Oda (2004) and was broadcast on Fuji TV in August 2007. This animation carries the theme of forests in Japan by telling the struggle of a teenager named Miyori with his friends to save the Komori Forest from those who want to turn the forest into a dam. With the story of environmental preservation as entertainment for all ages, the animation Miyori no Mori packs a moral education message with the primary setting of the forest and environment. Besides the environmental learning and moral, educational values, the animation also presents the characters adapted from Japanese myths and beliefs. The myths and beliefs present are interesting, considering that Japan, with all its modernization, still believes in things such a myth. That opinion confirms that Japan is a country that upholds traditional values which are believed to be part of Shinto and Buddhist teachings. Through this animation, the audience knows more about Japanese mythology and beliefs directly related to the forest around them.

The existence of traditional culture and elements of Japanese people's beliefs in the animation encourages researchers to know more clearly about the critical role in the elements of Japanese people's beliefs. For this purpose, in this study, the researcher will use the sociology of literature to analyze the elements of belief that developed in Japanese society through the anime Miyori no Mori. According to Ratna (2004), the sociology of literature analyzes literary works about society. The analysis model includes three types, (1) analyzing social problems in the literary work, then connecting them with the facts in the community, (2) analyzing social problems in literary works by finding the relationship between their structures, and (3) analyzing the literary work with specific purposes to obtain certain information, by particular approach [7]. 


\subsection{Japanese Beliefs}

Shinto is a traditional belief of Japanese society, which became the country's official religion since the Meiji restoration. As an ancient belief, Shinto teachings are deeply embedded in the soul of Japanese society so that it becomes an identity for the people. Shinto is a teaching that glorifies the harmonization of human life with nature. According to Shaw (through Andini), Shinto belief teaches that humans are an inseparable part of nature. All seem to have a relationship with each other in a web of interdependence, both space and time or the law of cause and effect. That states that the Japanese belief is that every human being has a reikon (soul/spirit). When someone dies and gets a proper funeral, their reikon will join the ancestors and protect their family. However, when someone dies unnaturally (killed or suicide) or still has hatred, revenge, and sadness, their reikon will transform into yurei. Both ancestors and yurei are believed to live in a natural environment close to humans. As a popular belief, Shinto believes that the entire universe is the abode of the gods or kamigami in Japanese. Kamigami is not limited to just staying in a specific place but can also dwell on an object. That is why followers of the Shinto religion must preserve and respect the universe [8].

\section{Discussion}

Before discussing the existence of forests in Japanese beliefs, researchers will first explain the forest and environment depicted in the anime Miyori no Mori. It is intended to obtain a clearer picture of Japanese belief forms in a visual one. Considering that the discussion is about forests and their environment, the following presentation will only discuss the forest, which is part of the background of the anime Miyori no Mori.

\subsection{Forests in the Japanese Belief}

In In Shinto teachings, the belief in the harmonization of the kami power becomes crucial. The existence of kami is in every natural object, such as mountains, forests, waterfalls, and winds. With kami in the natural object, it is believed that kami will guide the straight path so that everyone can live according to the path of truth. Those teachings are why most of the temples in Japan are surrounded by forests and everything related to nature. The Shinto religion believes that kami brings both blessing and disaster to human life. Therefore if kami are not worshipped adequately or neglected, they might bring evil or behave violently and destructively. However, if the kami are worshipped well, they will bring blessings upon society [9].

The Japanese people believe that several types of trees have special features related to us. Some of them are ogatamanoki (believed that the tree has an extraordinary power to invite a god's soul ); matsu (when placed in front of the door, means waiting for god's soul to descend from heaven); sakaki (which has been used to purify areas and distinguish holy place for Shinto god is in shrines [10]; bamboo (a symbol of good luck), dan peach tree (was believed to have extraordinary power that can drive away devils or thunder). In addition, there is also public belief in the existence of large trees, which they call kodama.

Kodama means a tree guardian deity that is believed to guard the trees in Japanese forests. Kodama is also believed to be the spirit of the tree itself. In Shinto teachings, kodama is said to be a god who is relatively calm [11]. Kodama is also known as jiyushin, which refers to the god who resides in the tree. Japanese people believe that trees are also the dwelling place for spirits who offer protection and control over the surrounding houses. Generally, kodama is worshipped by priests, forest rangers, and domestic people to harmonize their lives with 
the surrounding forest. A tree to be inhabited by the kodama is usually marked with a rope called a shimenawa. This symbol refers to the honour of the god who resides in kodama.

When viewed from the Shinto teachings that have been firmly embedded in the lives of Japanese society, it can be understood how their attitudes in protecting their surrounding natural environment are closely related to something scary. That can be seen from their belief in the form of forest animals that are related to kamigami. These animals are believed to have good and bad effects on human life. These animals such as kitsune (fox), tanuki (raccoon dog), tengu (a monster in the form of a crow), and kappa (a monster in the shape of a turtle).

\subsection{Forest and Myth in Anime Miyori no Mori}

The close relationship between humans and nature is inseparable. The belief that nature itself is a part that consists of positive and negative energy that can cause good and bad nature (evil) makes them believe that they must ask for the protection of the gods so that they can still live in the truth that well synergizes with nature. That statement is clearly illustrated in the anime Miyori no Mori. The forest in anime is named Komori and described as a reasonably large area located adjacent to a village's settlements. The grove of trees depicted gives the impression that this forest can be categorized as a rain forest where various trees and animals are contained. The existence of close-together trees, the forest atmosphere that seems dark increasingly shows that the forest is a protected area. Besides hilly areas, there is also a large lake in the forest's depths in that forest. Besides that, a large tree seems to be the centre of other creatures "s life in that forest.

The illustration of Komori in that animation builds the audience's imagination about the Japanese mystery in the forest. The condition of the quiet forest, the path that is surrounded by trees and rows of houses with traditional nuances with raw materials from nature, is as if the image of rural Japanese people who always try to live side-by-side with the forest surrounds their village. The belief that the forest is the dwelling place of the kamigami makes the villagers maintain the balance of human life with the visible creatures that inhabit their forests. They believe that if they need protection from the kamigami, they should protect the forest area where the gods live.
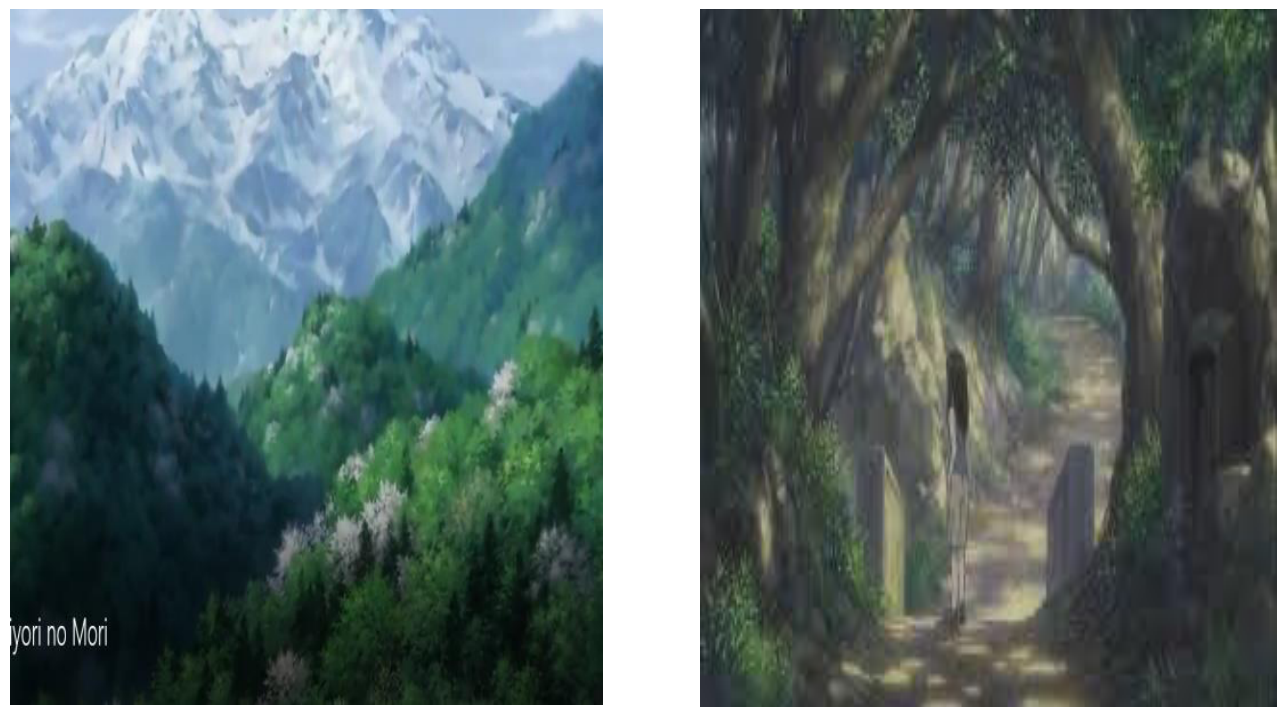

Fig. 2. Caption of the Komori forest illustration [12]. 

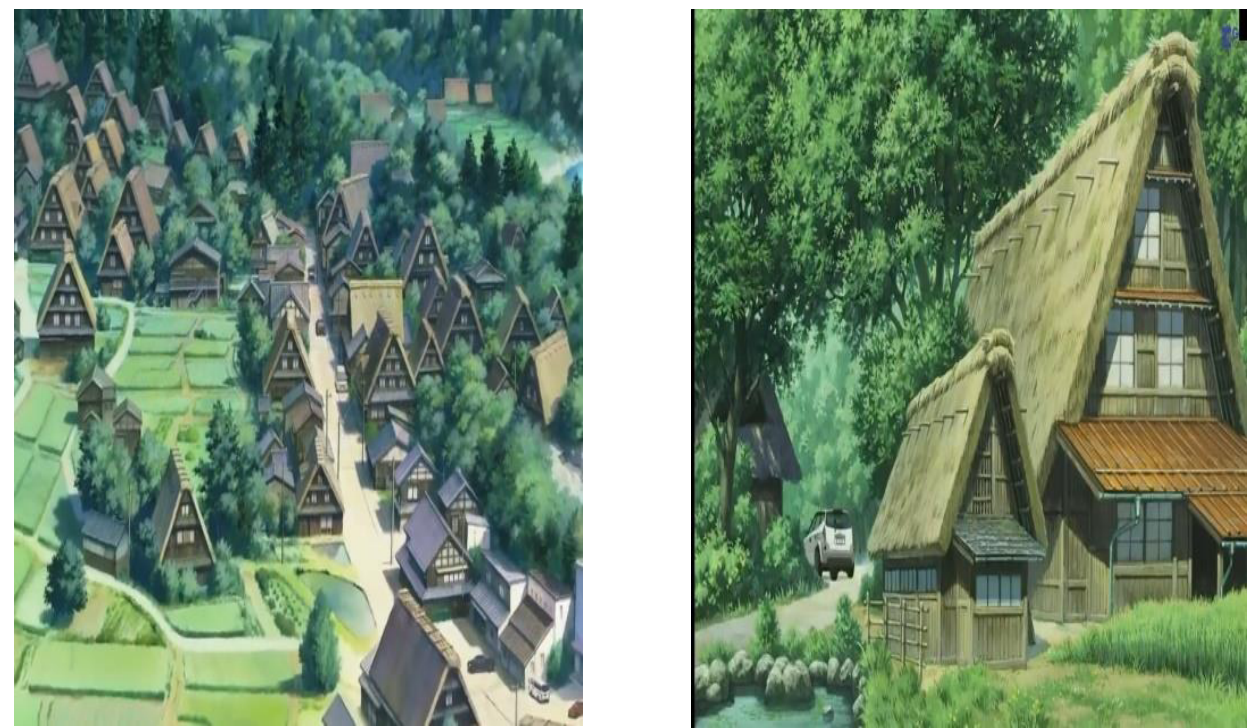

Fig. 3. Caption of the Komori village illustration.

The belief that nature itself is a part that consists of positive and negative energy that can cause good and bad nature (evil) creates a picture of forest dwellers who became a myth of Japanese society. Following the Japanese people's beliefs, the number of gods is enormous and can take shape in any form. In the anime Miyori no Mori, creatures that might consist of gods, ancestral spirits, and even monsters carry bad influences. However, from various illustrations of forest dwellers, some animation characters are mythical creatures known to Japanese people. Here are some of these mythical creatures.

- Ipponzakura

In the anime Miyori no Mori, this figure is depicted as a highly adored goddess and respected by all forest dwellers. In Japanese belief, this figure represents the goddess who guards the forest and the surrounding environment and resides in a kodama.
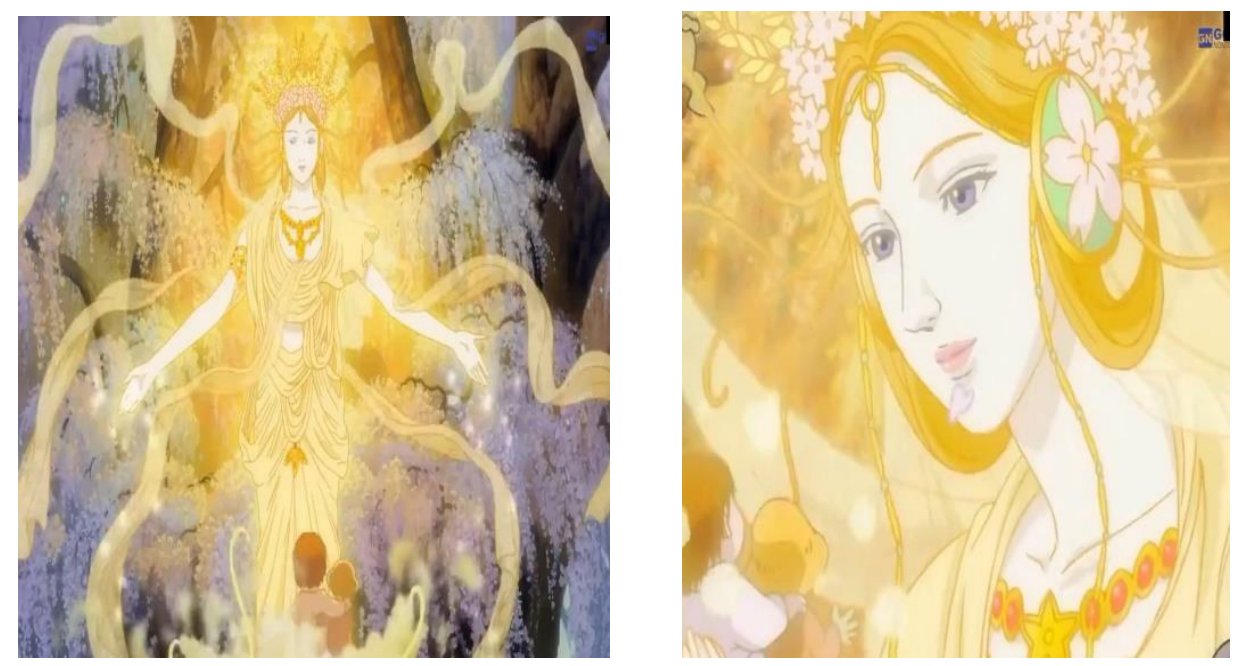

Fig. 4. Caption of Ipponzakura illustration.

- Kappa 
Kappa is a creature that resides in the rivers. The figure of kappa is a turtle with a massive shell on his back. In this anime, the figure of kappa is depicted as the possessor of a lake in the Komori forest.

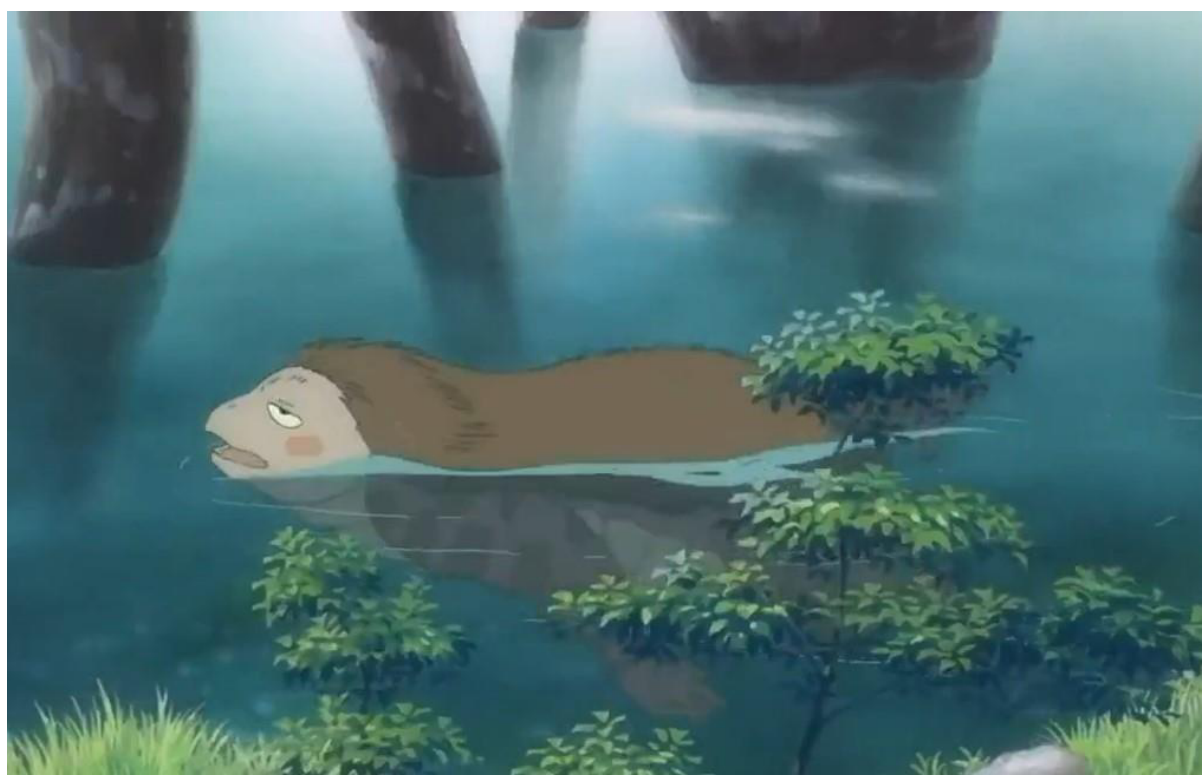

Fig. 5. Caption of kappa illustration.

\section{- Yurei}

Yurei is believed as a reikon who is still trapped between the human world and the world of immortals because he/ she died unnaturally or left a problem unfinished. In the anime Miyori no Mori, the yurei figured as a woman who still holds a grudge against a man who hurt her. Her hatred makes her hates all kinds of men, so she will attack every man who enters the forest where she lives.
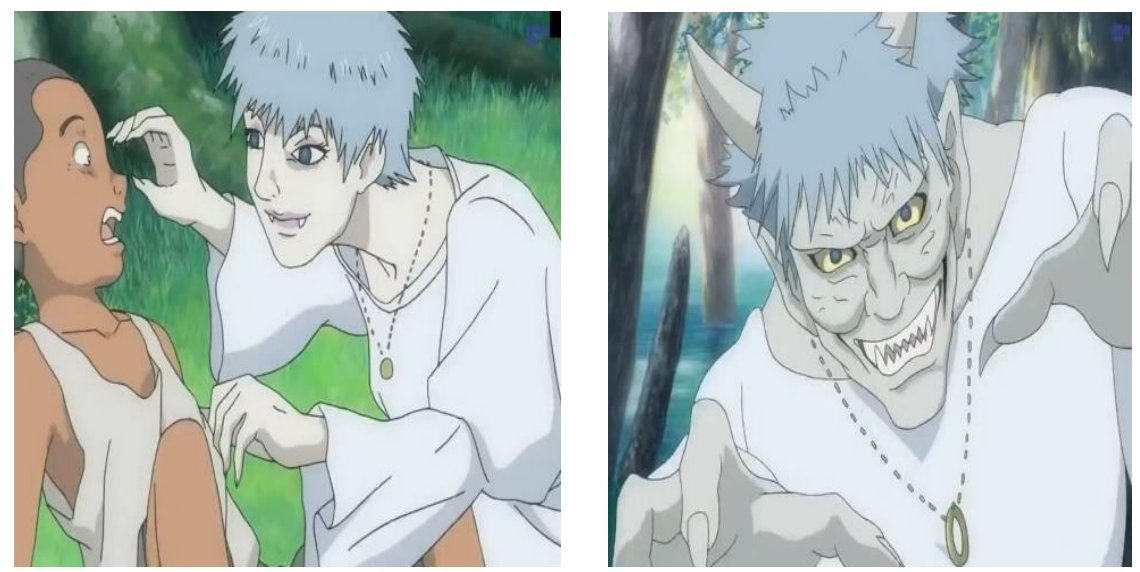

Fig. 6. Caption of Yurei illustration.

- Kodama

A sakura blossom tree represents the kodama, which is believed to be the dwelling place for gods and ancestral spirits in the forest in this anime. It is told in the anime that this 
kodama is the dwelling place of the goddess of sakura. She is the Komori forest guard and lives in the vast death tree. However, even though it has been a long-dead tree, this Kodama will turn beautiful when the goddess is present among other residents. The belief that the goddess of sakura is protecting the forest is residing there, the people of Komori village worships the Kodama tree. That can be seen from the presence of shimenawa (rope knots) wrapped around the tree.

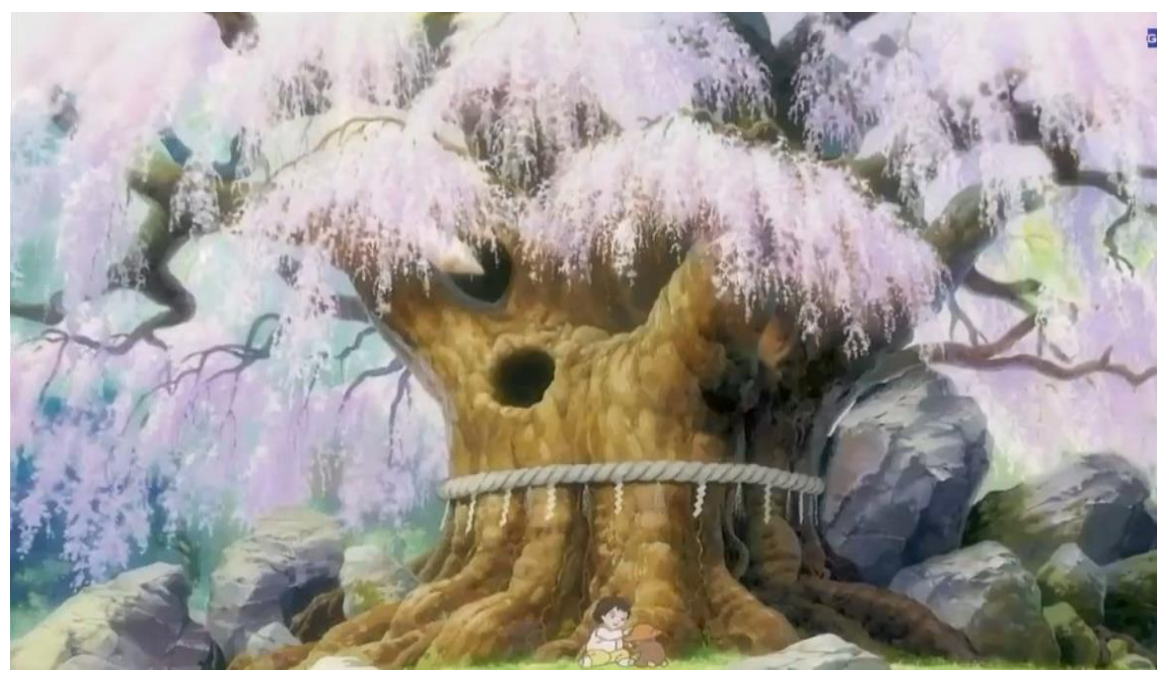

Fig. 7. Caption of Kodama illustration.

\section{Conclusion}

Based on the analysis results, it can be concluded that the attachment of Japanese society to nature has become a tradition passed down from generation to generation. Shinto teachings that become a national identity can even be seen from various forms of literary works. From their work, we can see that their belief in things outside their life is still well preserved even when they have entered the modern era with technological advances. As part of their balance in living side by side with nature, a forest is a place that is very well preserved. The community has made Japanese efforts to maintain the existence and sustainability of the forests they own. The existence of forests for Japanese people is not only due to the vital position of forests as the lungs of the world amid polluting industrialization, but more than that, the existence of forests is vital because it is where all parts of their religious rituals reside. For the Japanese, a forest exists as the residing guardian deity, a place for the spirits of their ancestors who will always come to visit during the Obon festival, and a temporary resting place for spirits still tied to a human world. Forests are their pulse and a place to connect with what they worship. Japanese believed that when we continue to make an effort to maintain the existence and sustainability of the forests, then we can get a whole lifetime of protection from the kamigami and the protector ancestors who live in the forest side by side with a human world, including the protection from global diseases effects such as covid19. So, as long as Shinto beliefs and teachings are well preserved, then the existence of the forest will remain an essential part of the life of Japanese society. 


\section{References}

1. A. R. Andini, Identitas dan kebijakan luar negeri: Komitmen Jepang terhadap penanganan illegal logging di Indonesia dalam kerangka Asia forest partnership tahun 2002 - 2012, Journal of International Relations, 3,1 (2017)

2. https://www.shinrin-ringyou.com

3. A. Rots, Sacred forests, sacred nationality: The Shinto environmentalist paradigm and the rediscovery of "Chinju no Mori", Japanese Journal of Religious Studies, 42, 2 (2015)

4. https://www.nippon.com

5. B. Mulyadi, ENIS model of environmental education for elementary school students in Japan, in Proceedings of the 5th International Conference on Energy, Environmental and Information System (ICENIS), Semarang, Indonesia, (2020)

6. F. Noviana, Semiotic study of Japanese views on sea in Hayao Miyazaki's Ponyo on the cliff by the sea, in Proceedings of the 5th International Conference on Energy, Environmental and Information System (ICENIS), Semarang, Indonesia, (2020)

7. K. Ratna, Teori. metode, dan tehnik penelitian sastra, (Pustaka Pelajar, Yogyakarta, 2004).

8. Y. Rahmah, Omamori: Harmonization of Humans and Their Environment in Cultural Symbols, in Proceedings of the 5th International Conference on Energy, Environmental and Information System (ICENIS), Semarang, Indonesia, (2020)

9. http://sanpai-japan.com

10. O. Hiroshi, Trees, forests and religion in Japan, Mountain Research and Development Journal, 24, 2 (2004)

11. Dewinta, Kodama pada Ajaran Shinto sebagai Kearifan Lokal terhadap Kelestarian Hutan di Jepang, (Japanese Literature Study Program, Sumatera Utara University, 2018)

12. Nippon. Animation.Fuji TV.Miyori no Mori. (Television Broadcast Tokyo Public Broadcasting Service, 2007) 